\title{
Incidence and Risk Factors for Follow-Up Interruption of HIV-Infected Patients in Guadeloupe
}

Narcisse Elenga ${ }^{1}$, Marie-Thérèse Georger-Sow ${ }^{2}$, Thierry Messiaen ${ }^{3}$, Isabelle Lamaurie ${ }^{3}$, Isabelle Favre ${ }^{3}$, Mathieu Nacher ${ }^{1,4}$ and Gilles Beaucaire $^{3}$

${ }^{1}$ Service de Pédiatrie, Centre hospitalier de Cayenne «Andrée Rosemon», Rue des Flamboyants, BP 6006-97306 Cayenne cedex, Guyane Française ${ }^{2}$ Coordination Régionale VIH (COREVIH) Guadeloupe CHU de Pointe-à-Pitre/Abymes Bâtiment B Ancien Hôpital Ricou 2 ème étage BP 46597159 Pointe-à-Pitre Cedex, Guyane Française

${ }^{3}$ Service des maladies infectieuses, Guadeloupe CHU de Pointe-à-Pitre/Abymes Bâtiment B Ancien Hôpital Ricou 2ème étage BP465 97159 Pointe-à-Pitre Cedex, Guyane Française

${ }^{4}$ Coordination Régionale VIH (COREVIH) Centre hospitalier de Cayenne "Andrée Rosemon », Centre d'Investigation Clinique Epédémiologie Clinique CIC EC Antilles Guyane CIE 802, Guyane Française

\begin{abstract}
Background: Guadeloupe is the region of France with the second highest prevalence of HIV.

Methods: To determine the risk factors for being lost to follow-up (LFU), a retrospective cohort study of 2,732 patients followed between 1988 and 2009 was conducted, and determined which variables were related to being LFU, i.e. permanently disappearing from HIV clinics or coming back after more than one year of missed appointments.

Results: The incidence rate for permanent follow-up interruption was 9 per 100 person-years (8.3-9.7 personyears). The median time of LFU was 6.4 years (interquartile range 3-16.9 years). Cox modelling showed that the younger age groups (HR: 1.60[1.30-2.10], $p=0.000$ ) and patients diagnosed before 1997 (HR: 4.80[3.50-6.50], $p=0.000$ ) were significantly more likely to be permanently LFU. However, patients treated with HAART had a lower risk of being LFU (HR: 0.63[0.51-0.80], $p=0.000)$.
\end{abstract}

Conclusion: These results suggest that some patients may have died. They also allow to quantify the magnitude of a major yet often under-recognized problem and to identify its predictors in the context of Guadeloupe. This could help clinicians improve patient retention.

Keywords: HIV-infected patients; Follow-up interruption; Risk factors; Guadeloupe

Abbreviations: HIV: Human Immunodeficiency Virus; AIDS: Acquired Immunodeficiency Syndrome ; LFU: Lost to Follow-Up; HR: Hazard Ratio; HAART: Highly Active Antiretroviral Therapy; GFHDH: Guadeloupe Section of the French Hospital Database for HIV; GHDH: Guadeloupean Hospital Database on HIV infection; CISIH: Centre d'Information et de Soins de l'Immunodéficience Humaine ; RNA: Ribonucleic Acid; INSERM: Institut National de la Recherche Médicale; CNIL: Commission Nationale Informatique et Libertés; CDC: Centers for Disease Control and Prevention; IQR: Interquartile Range

\section{Introduction}

Guadeloupe is part of the French overseas territories, and has a large number of persons living with HIV/AIDS. Transmission is mostly heterosexual, and the proportion of infected women is high, i.e. almost half of all those infected. Moreover, in Guadeloupe, a large proportion of patients are foreigners (mainly from Haiti) [1,2]. The standards of healthcare in Guadeloupe are similar to those of metropolitan France. All patients infected with human immunodeficiency virus (HIV) may receive free antiretroviral treatment (including the most recent drugs) regardless of their nationality or their socio-economic level. Radiology, viral loads, CD4 counts and HIV genotyping, as well as antiretroviral drug monitoring are available for routine care. Since 1996, the use of highly active antiretroviral therapy (HAART) in developed countries has led to a decrease in the morbidity and mortality of patients infected with HIV [3,4]. However, despite the availability of more effective treatments for HIV infection, some patients under care stop their clinical follow-up. These patients are at major risk of developing AIDSdefining illnesses leading to death. A recent analysis of data from the Guadeloupe section of the French Hospital Database for HIV (GFHDH) suggested a persistently high proportion of late presenters for HIV diagnosis and HIV care in Guadeloupe [5]. The follow-up of patients is of paramount importance to measure their immunovirological status and eventually start or optimize anti-retroviral therapy, and to screen for and prevent HIV-related morbidity and mortality. In Guadeloupe, no data have been reported regarding patients who are lost to followup. This study aimed to describe predictors of loss to follow-up (LFU) in the Guadeloupean Hospital Database on HIV infection (GHDH).

\section{Materials and Methods}

\section{Description of the FHDH}

GHDH is part of the French Hospital Database on HIV. The characteristics of the FHDH have been described in detail elsewhere [6]. Briefly, FHDH is a clinical epidemiological network implemented, since 1992, in 62 French University Hospitals belonging to 29 HIV treatment and information centres (CISIH) located both in continental France and overseas territories. The only FHDH inclusion criteria are

*Corresponding author: Narcisse Elenga, Service de Pédiatrie, Centre hospitalier de Cayenne, Andrée Rosemon, Rue des Flamboyants, BP 6006-97306 Cayenne cedex, Guyane Française, Tél: +595 694978048 ; Fax: +594 594394 819; E-mail: elengafr@yahoo.fr

Received July 30, 2013; Accepted August 28, 2013; Published September 03, 2013

Citation: Elenga N, Georger-Sow M-T, Messiaen T, Lamaury I, Favre I, et al. (2013) Incidence and Risk Factors for Follow-Up Interruption of HIV-Infected Patients in Guadeloupe. J AIDS Clin Res 4: 238. doi: 10.4172/2155-6113.1000238

Copyright: (C) 2013 Elenga N, et al. This is an open-access article distributed under the terms of the Creative Commons Attribution License, which permits unrestricted use, distribution, and reproduction in any medium, provided the original author and source are credited. 
documented HIV-1 or HIV-2 infection and written informed consent. Data are recorded prospectively by trained research assistants, using DMI2 software (property of the French Ministry of Health). The standardised data collection form includes baseline characteristics, the usual biologic markers such as CD4 cell counts and plasma HIV-RNA levels, clinical manifestations, treatments, clinical trials in which the patients are enrolled, death, and the cause of death, as reported in the medical records.

\section{Patients}

The HIV-positive patients followed in Guadeloupe since 1 January 1988 and at St. Martin Hospital since 1 January 1992 until 31 December 2009 were enrolled in the GFHDH. Time-independent variables such as sex, nationality, and contamination mode and time-dependent variables such as age, CD4 counts, HIV1 viral loads, treatments, and clinical events are routinely entered by trained clinical studies technicians. Patients included in the FHDH gave informed consent for the use of their data. Their identity was encrypted before the data were sent to the Ministry of Health and the Institute National de la Recherche Médicale (INSERM), which centralises data from the Centres for Information and Care of HIV (CISIH) throughout France. This data collection was approved by the Commission Nationale Informatique et Libertés (CNIL), a national committee that oversees research data.

\section{Definition of patients lost to follow-up (LFU)}

Patients were considered permanently LFU if they had permanently disappeared from HIV clinics, excluding patients known to be deceased. Temporary interruption of follow-up was defined as a period of more than 1 year before consulting again [7].

\section{Variables}

Age was divided into three groups: $<30$ years, $30-40$ years, and $>40$ years. The other explanatory variables were gender, drug addiction (alcohol, marijuana smoking, crack or cocaine use), HIV diagnosis period, CD4 count at enrolment (categorised as $<200,200-499$, and $\geq 500$ cells $/ \mathrm{mL}$ ), CDC categories A, B, and C, ART initiation period, and history of psychiatric problems during follow-up. We created three categories for period of inclusion: 1988-1996, 1997-2004 and 20052008.

\section{Statistical analysis}

The factors associated with LFU were analysed by Cox models yielding adjusted hazard ratios (HR). For all tests performed, a p-value of 0.05 or less was considered as statistically significant. The data were analysed with STATA 10.0 (Stata Corp LP, College Station, TX, USA). The proportionality of the hazard functions was determined graphically and using Schoenfeld residuals. A total of 2732 subjects with 46722 observations were included in the analysis, representing a total of 6909 person-years of follow-up.

\section{Results}

Overall, there were 1173 women (43\%) and 1559 men (57\%). Among these patients, $20 \%$ had received highly active antiretroviral therapy (HAART) (57\% if considering the period starting in 1996). 735 (27\%) were less than 30 years of age, 986 (36\%) were between 30 and 40 years of age, and 1341 (49\%) were more than 40 years old. There were 610 permanent loss to follow-up events (incidence rate, 9 per 100 person-years) for an observation period of 6,909 person-years. The median follow-up was 1.7 years (interquartile range [IQR] $0-18$ ). The median time to failure was 6.4 years (IQR 3-16.9 years).
Table 1 shows that patients in the younger age group and patients diagnosed before 1997 were most likely to be LFU while patients treated with HAART had a low risk of being LFU. Table 2 globally shows the similar risk factors than Table 1.

Figure 1 shows that the incidence of follow up interruption decreases over time periods. It also shows that the incidence was higher in the first months after the patient enters care.

\section{Discussion}

More than $22 \%$ of the patients from our cohort were permanently LFU. This proportion is high but it is lower than in French Guiana where a third of the cohort was permanently lost to follow up. This study shows some of the factors underlining this high rate of loss to follow-up in Guadeloupe. Younger patients, earlier year of HIV diagnosis, patients not receiving any treatment, and patients diagnosed with a moderate CDC stage where more likely to disappear. This confirms other studies performed in HIV patients [8]. Guadeloupe, like French Guiana, takes in large numbers of clandestine immigrants from neighbouring countries. Irregular immigrants may try to avoid all contact with the local authorities, including health authorities, to avoid expulsion, and may also encounter added economic and linguistic difficulties. In French Guiana [8], foreigners and patients without residence permits also seemed more likely to be LFU. Indeed, socio-economic difficulties

\begin{tabular}{|c|c|c|c|}
\hline Variable & $\begin{array}{c}\text { Incidence rate } \\
(/ 100 \text { person-years })\end{array}$ & $\begin{array}{l}\text { Hazard ratio* } \\
(95 \% \mathrm{Cl})\end{array}$ & $\mathbf{p}$ \\
\hline \multicolumn{4}{|l|}{ Age } \\
\hline$\leq 30$ & 14 & $1.6(1.30-2.10)$ & 0.000 \\
\hline $30-40$ & 8.6 & $1.30(1.10-1.60)$ & 0.012 \\
\hline$>40$ & 5 & 1 & \\
\hline \multicolumn{4}{|l|}{ Gender } \\
\hline Female & 7 & 1 & \\
\hline Male & 8 & $1.10(0.90-130)$ & 0.5 \\
\hline \multicolumn{4}{|l|}{ HIV diagnosis period } \\
\hline $2005-2008$ & 2.5 & 1 & \\
\hline $1997-2004$ & 7 & $3.10(2.26-4.23)$ & 0.000 \\
\hline $1988-1996$ & 14 & $4.8(3.50-6.50)$ & 0.000 \\
\hline \multicolumn{4}{|l|}{ CD4 cell count } \\
\hline Initial CD4<200/mm ${ }^{3}$ & 3 & $0.47(0.34-0.65)$ & 0.000 \\
\hline 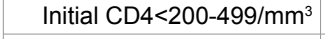 & 7.3 & $0.82(0.68-0.98)$ & 0.032 \\
\hline Initial CD4>500/mm 3 & 11 & 1 & \\
\hline \multicolumn{4}{|l|}{ CDC categories } \\
\hline$A$ & 11 & 1 & \\
\hline B & 6 & $0.70(0.53-0.85)$ & 0.001 \\
\hline C & 2.7 & $0.38(0.28-0.53)$ & 0.000 \\
\hline \multicolumn{4}{|l|}{$\begin{array}{l}\text { Known drug } \\
\text { use/addiction }\end{array}$} \\
\hline no & 8 & 1 & \\
\hline yes & 10 & $0.7(0.31-1.50)$ & 0.4 \\
\hline \multicolumn{4}{|l|}{ ARV therapy } \\
\hline HAART+ & 4 & $0.63(0.51-0.80)$ & 0.000 \\
\hline HAART- & 12 & 1 & \\
\hline
\end{tabular}

*Obtained using a Cox proportional hazard model including all the above mentioned covariates.

$\mathrm{Cl}$ : confidence interval; py: person-years

Table 1: Risk factors for permanent follow-up interruption of HIV-infected patients in Guadeloup. 


\begin{tabular}{|c|c|c|c|}
\hline Variable & $\begin{array}{c}\text { Incidence rate } \\
\text { (/100 person-years) }\end{array}$ & $\begin{array}{l}\text { Hazard ratio* } \\
(95 \% \mathrm{Cl})\end{array}$ & p \\
\hline \multicolumn{4}{|l|}{ Age } \\
\hline$\leq 30$ & 14 & $1.62(1.25-2.10)$ & 0.000 \\
\hline $30-40$ & 8.6 & $1.40(1.10-1.72)$ & 0.000 \\
\hline$>40$ & 4.7 & 1 & \\
\hline \multicolumn{4}{|l|}{ Gender } \\
\hline Female & 7 & 1 & \\
\hline Male & 8 & $1.05(0.89-1.30)$ & 0.60 \\
\hline \multicolumn{4}{|l|}{ HIV diagnosis period } \\
\hline $2005-2008$ & 2.5 & 1 & \\
\hline 1997-2004 & 7 & $1.15(0.92-1.42)$ & 0.20 \\
\hline 1988-1996 & 14 & $1.64(1.31-2.10)$ & 0.000 \\
\hline \multicolumn{4}{|l|}{ CD4 cell count } \\
\hline Initial CD4 < 200/mm ${ }^{3}$ & 2.8 & $0.80(0.60-1.10)$ & 0.082 \\
\hline 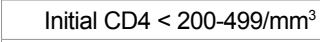 & 7 & $1.10(0.92-11.30)$ & 0.30 \\
\hline Initial CD4 > 500/mm ${ }^{3}$ & 11 & 1 & \\
\hline \multicolumn{4}{|l|}{ CDC categories } \\
\hline A & 11 & 1 & \\
\hline B & 6 & $0.78(0.63-0.79)$ & 0.025 \\
\hline $\mathrm{C}$ & 2.7 & $0.72(0.57-0.91)$ & 0.006 \\
\hline \multicolumn{4}{|l|}{ Known drug use/addiction } \\
\hline no & 7.5 & 1 & \\
\hline yes & 10 & $1.80(1.20-2.80)$ & 0.01 \\
\hline \multicolumn{4}{|l|}{ ARV therapy } \\
\hline HAART+ & 3.9 & $0.24(0.19-0.30)$ & 0.000 \\
\hline HAART- & 11 & 1 & \\
\hline
\end{tabular}

*Obtained using a Cox proportional hazard model including all the above mentioned covariates.

$\mathrm{Cl}$ : confidence interval; py: person-years

Table 2: Risk factors for temporary follow-up interruption of HIV-infected patients in Guadeloupe.

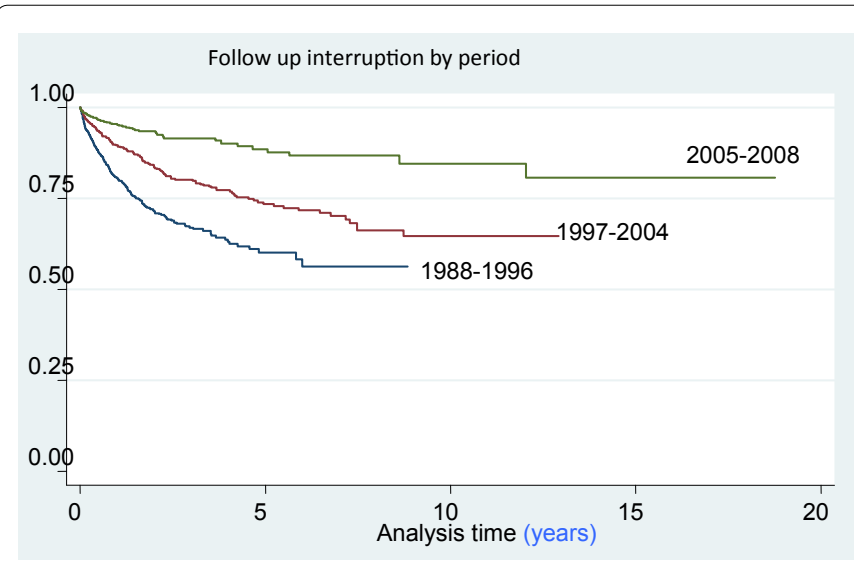

Figure 1: Kaplan-Meier estimates representing the survival function with follow up interruption as failure event, over time"1988-2008 hospital cohort in Guadeloupe $(n=2732)$.

may have led patients to rank medical follow-up low in their priorities [9]. In addition, immigrants are geographically mobile by definition. Therefore, they would also seem more likely to move elsewhere in search of better living conditions or to go back to their country of origin for extended periods either voluntarily or constrained by immigration authorities. A study by Couppié and colleagues in French Guiana [10] showed that, before the availability of HAART, $48 \%$ of foreign HIV patients returned to their country of origin. Although some patients may have consulted a practitioner who is not included in the FHDH, the increased risk of permanent loss to follow-up in untreated patients and patients in the CDC category B stage suggests that some patients died without benefiting from specialised care. There are numerous definitions of LFU from HIV literature and the choice of a LFU definition can affect the quality of study conclusions [11]. However, one of the difficulties of the definition used in this study is that we could not know for sure if patients LFU were still alive. This is why we looked at a milder version of loss to follow-up defined as patients coming back after more than 1 year. These patients may also have greater geographical and social instability (finding a stable job or a stable partner). The fear of being identified as HIV positive could be greater for those who are still looking for a stable partner. In our study, due to low number of indicated patients, it was impossible to analyse certain socioeconomic variables such as residence permits and education. Patients are often LFU at the early stages of infection and come back into the medical circuit at very advanced stages of immunodepression, after a long period of traditional "treatments." In a previous study [8], CD4 counts of more than 500 per $\mathrm{mm}^{3}$ were associated with the temporary disappearance of patients. This suggests that these patients may not feel any tangible symptoms of HIV infection and thus do not perceive the benefits of strict follow-up.

The above mentioned factors have also been shown to predict appointment attendance in the United States [12]. The facts that treated patients are less likely to be LFU and that patients in general have been less likely to disappear since the availability of HAART suggest that when patients understand the treatment benefits, they are more likely to come back if they have hope of improving their health. Physicians should underline the importance of follow-up, especially if patients do not receive treatment. Too often patients interrupt their follow up yet are never contacted by the hospital, thus giving the impression that the hospital does not notice. The most straightforward and perhaps operationally feasible solution is to call every patient that does not show at the consultation in order to give another appointment, thus keeping contact and showing concern. Although the incidence of follow up interruption has declined in recent periods, it was always highest in the first months following care initiation. Therefore, new patients should be of particular concern, and promptly recontacted when missing appointments.

There are several limitations to the present analyses. Firstly, the results found for a particular French clinical cohort cannot be extrapolated to other locations, because risk factors for LFU may be determined by the nature of the population, the place of residence, and/ or the methods of tracking and of keeping patients in care. Nevertheless, several sociodemographic and clinical variables found here to be associated with LFU seem to be common to many other studies. Secondly, although chart information was updated some patients might have been followed in another HIV centre in a different geographical area. We may therefore have overestimated the incidence rate of LFU. In addition, because we did not match our LFU data with National Death Index registries, we may have considered deceased patients as LFU. Thirdly, although the data for most of the sociodemographic and clinical variables were prospectively collected, the study was designed after data collection had ended. 
Citation: Elenga N, Georger-Sow M-T, Messiaen T, Lamaury I, Favre I, et al. (2013) Incidence and Risk Factors for Follow-Up Interruption of HIV-Infected Patients in Guadeloupe. J AIDS Clin Res 4: 238. doi: 10.4172/2155-6113.1000238

\section{Conclusion}

We attempted to quantify and identify predictors of follow up interruption of HIV patients in Guadeloupe. This information may help clinicians improve HIV-patient retention and thereby reduce morbidity and mortality, and promote risk reduction.

\section{Acknowledgements}

The authors would like to thank the members of the Guadeloupean HIV Cohort Study for data collection.

\section{References}

1. Infection à VIH et sida (2013) Base de données VIH.

2. Cadelis G, Rossigneux E, Millet J, Rastogi N (2012) [Comparative epidemiological study of the tuberculosis - migrant and native subjects in Guadeloupe from 2006 to 2011]. Rev Mal Respir 29: 858-870.

3. Palella FJ Jr, Delaney KM, Moorman AC, Loveless MO, Fuhrer J, et al. (1998) Declining morbidity and mortality among patients with advanced human immunodeficiency virus infection. HIV Outpatient Study Investigators. N Engl J Med 338: 853-860.

4. Moore RD, Chaisson RE (1999) Natural history of HIV infection in the era of combination antiretroviral therapy. AIDS 13: 1933-1942.

5. Elenga N, Georger-Sow MT, Nacher M (2012) Risk factors for late presentation for are among HIV-infected patients in Guadeloupe: 1988-2009. J AIDS Clin Res 3: 166.
6. Nacher M, Adriouch L, Godard Sebillotte C, Hanf M, Vantilcke V, et al. (2010) Predictive factors and incidence of anxiety and depression in a cohort of HIVpositive patients in French Guiana. AIDS Care 22: 1086-1092.

7. Chi BH, Yiannoutsos CT, Westfall AO, Newman JE, Zhou J, et al. (2011) International Epidemiologic Databases to Evaluate AIDS Collaboration. Universal definition of loss to follow-up in HIV treatment programs: a statistical analysis of 111 facilities in Africa, Asia, and Latin America. PLoS Med 8: e1001111.

8. Nacher M, El Guedj M, Vaz T, Nasser V, Randrianjohany A, et al. (2006) Risk factors for follow-up interruption of HIV patients in French Guiana. Am J Trop Med Hyg 74: 915-917.

9. Lanoy E, Mary-Krause M, Tattevin P, Dray-Spira R, Duvivier C, et al. (2006) Predictors identified for losses to follow-up among HIV-seropositive patients. J Clin Epidemiol 59: 829-835.

10. Couppié P, Clyti E, El Guedj M, Sobesky M, Pradinaud R (2002) Social factors associated with bad follow-up with HIV+ patients in French Guiana. XIII ${ }^{\text {th }}$ International AIDS Conference, Barcelona, Spain, July 7-12.

11. Shepherd BE, Blevins M, Vaz LM, Moon TD, Kipp AM, et al. (2013) Impact of Definitions of Loss to Follow-up on Estimates of Retention, Disease Progression, and Mortality: Application to an HIV Program in Mozambique. Am $J$ Epidemiol .

12. loannidis JP, Bassett R, Hughes MD, Volberding PA, Sacks HS, et al. (1997) Predictors and impact of patients lost to follow-up in a long-term randomized trial of immediate versus deferred antiretroviral treatment. J Acquir Immune Defic Syndr Hum Retrovirol 16: 22-30. 